\title{
Fretting Fatigue Behaviour of Alloy Steel in the Very High Cycle Region
}

\author{
Yoshinobu SHIMAMURA ${ }^{1}$, Reo KASAHARA ${ }^{2}$, Hitoshi ISHII $^{1}$, Keiichiro TOHGO $^{1}$, \\ Tomoyuki FUJII ${ }^{1}$, Toru YAGASAKI ${ }^{2}$ and Soichiro SUMIDA ${ }^{2}$ \\ ${ }^{1}$ Department of Mechanical Engineering, Shizuoka University, 3-5-1 Johoku, Naka-ku, Hamamatsu, \\ Shizuoka 432-8561, Japan \\ ${ }^{2}$ Honda R\&D Co., Ltd., 4630 Shimo-Takanezawa, Haga-machi, Haga-gun, Tochigi 321-3321, Japan
}

\begin{abstract}
It is well known that fretting fatigue strength is much lower than the fatigue strength of smooth specimens and the fatigue limit disappears. Many studies on fretting fatigue have been reported but most of the studies have not cover fatigue properties in the very high cycle regime more than $10^{7}$ cycles. In this study, an accelerated fretting fatigue testing method was developed by using an ultrasonic torsional fatigue testing machine with a clamping fretting pad. Fretting fatigue tests of CrMo steel were conducted by using the developed method. Test results showed that fretting fatigue failure occurs in the very high cycle region.
\end{abstract}

\section{Introduction}

Accelerated fatigue testing machines are required in order to investigate fatigue properties in the very high cycle regime within practical testing periods, and an ultrasonic fatigue testing method using a piezoelectric oscillator is prospective one. Using an ultrasonic fatigue testing method enables us to reduce required time for fatigue tests to $1 / 100 \sim 1 / 1000$ compared with conventional fatigue test methods.

Authors have developed an ultrasonic torsional fatigue testing machine and investigated fatigue properties of carburized steels without internal fracture [1]. A fatigue crack initiated from the surface of a specimen during a torsional fatigue test because the maximum shear stress was applied to the surface. Thus, torsional loading is more suitable than axial loading for investigating fatigue properties of case hardening materials such as carburized steels.

Fretting is a phenomena that microscopic relative slips are repeated at a contact part. When cyclic stress is applied to a fretting part, the fatigue strength considerably decreases and the fatigue limit disappears. The phenomena is called fretting fatigue. Many studies on fretting fatigue have been reported but most of the studies did not cover fatigue properties in the very high cycle regime more than $10^{7}$ cycles. Sun et al. proposed an accelerated fretting fatigue testing method by using an ultrasonic tension compression fatigue testing machine [2]. However, as mentioned above, it is unsuitable for surface hardening materials. In this study, a new accelerated fretting fatigue testing method was developed by using an ultrasonic torsional fatigue testing machine with a clamping fretting pad. Fretting fatigue 
tests of CrMo steel were conducted by using the developed method in order to discuss the fretting fatigue damage in the very high cycle region.

\section{Experimental}

Material used in this study was quenched and tempered SCM420H. Table 1 shows the chemical composition. The Vickers hardness of specimen surface was $500 \mathrm{Hv}$.

Table 1. Chemical composition of SCM420H (in weight \%).

\begin{tabular}{|c|c|c|c|c|c|c|c|c|}
\hline $\mathbf{C}$ & $\mathbf{S i}$ & $\mathbf{M n}$ & $\mathbf{P}$ & $\mathbf{S}$ & $\mathbf{C u}$ & $\mathbf{C r}$ & $\mathbf{N i}$ & $\mathbf{M o}$ \\
\hline 0.21 & 0.21 & 0.77 & 0.02 & 0.02 & 0.11 & 1.02 & 0.06 & 0.18 \\
\hline
\end{tabular}

A schematic of an ultrasonic torsional fatigue testing machine is presented in Fig.1. Torsional vibration was generated by applying voltage to a piezoelectric oscillator. The resonance frequency was $20 \mathrm{kHz}$ and the torsional displacement amplitude was only a few $\mu \mathrm{m}$. The generated torsional amplitude of the oscillator was amplified using an amplifying horn. Further amplification of stress was achieved in a specimen. In this study, dumbbell shape specimens were used. The shape and shear stress/torsional angle distributions of a specimen is presented in Fig.2. The stress ratio $\mathrm{R}$ was -1 . The torsional displacement at the end of a specimen was measured by using a microscope during fatigue testing, and the shear stress distribution of a specimen was estimated by substituting the torsional displacement at the end of the specimen into FEA solution. Intermittent loading and compressed air cooling were simultaneously used to keep the temperature below $100^{\circ} \mathrm{C}$. Fatigue test was stopped when the resonance frequency decreased by $50 \mathrm{~Hz}$, or when the number of cycles exceeded $10^{9}$ cycles excluding one specimen up to $10^{10}$ cycles.

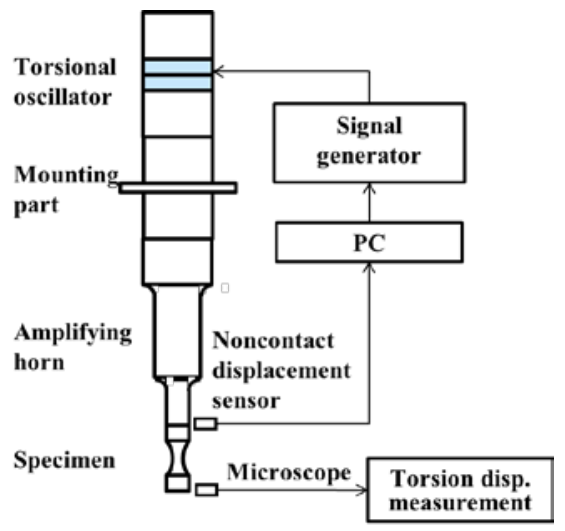

Fig. 1. Ultrasonic torsional fatigue testing machine. 


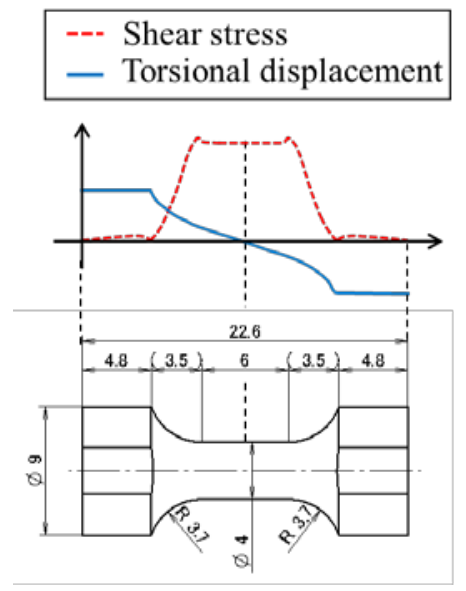

Fig. 2. Specimen shape and shear stress/torsional angle distributions.

Figure 3 shows a fretting fatigue specimen with a clamping fretting pad. Bridge-shaped contactors made of SKH51 were used. The Vickers hardness of the contactor was 730Hv. A contact load was provided by tightening bolts between two plate springs. An initial contact load can be measured by using a strain gage attached to one fretting pad. The initial contact load was set to be $800 \mathrm{~N}$ in this study. The temperature of the contactor was monitored during fatigue testing by thermocouple, and an increase in temperature was moderate; less than 10 degree. The fretting displacement can be controlled by changing the distance between two contact areas of a contactor. In this study, the fretting displacements ranges $100 \mu \mathrm{m}$ to $200 \mu \mathrm{m}$ at the fatigue crack initiation positions. The tangential force was not measured because it was difficult to determine the tangential force in this contact situation.
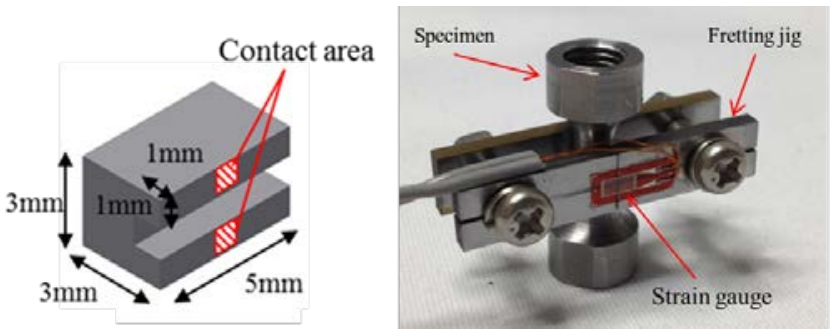

Fig. 3. Contactor and a specimen with a clamping fretting pad.

\section{Results and discussion}

S-N diagrams with and without fretting are shown in Fig.4. In the figure, symbols represent failure, where specimens have fatigue cracks long enough to decrease the natural frequency, while symbols with an arrow indicate run-outs. Fretting fatigue occurred in the very high cycle region, and the fretting fatigue strengths were much smaller than the fatigue strength of smooth specimens; the fatigue strength for smooth specimen at $10^{9}$ cycles was about 600MPa but that for specimens with fretting was about 160MPa.

In addition, fretting fatigue cracks were found even if the applied load was lower then $160 \mathrm{MPa}$. Figure 5 shows a wear part of a specimen at $10^{9}$ cycles for $\tau_{\mathrm{a}}=145 \mathrm{MPa}$. The 
surface length of fatigue cracks found at $10^{9}$ cycles ranged from 30 to $60 \mu \mathrm{m}$, implying that the fatigue cracks are non-propagating cracks $[3,4]$.

Finite element analysis was conducted to discuss the driving force of the fatigue crack initiation and propagation. The analytical model is shown in Fig.6; a half was modelled because of symmetry. The Young's moduli of specimen and contactor were set to be 203 $\mathrm{GPa}$, and $217 \mathrm{GPa}$, respectively, and the Poisson's ratios were both set to be 0.3. The friction coefficient at contact areas was set to be 0.6. The result showed that the orientations of initial fatigue cracks were almost perpendicular to the maximum principle stress amplitude direction, which was inclined about $30^{\circ}$ from the specimen axis. Since the maximum principle stress amplitude direction for pure torsion is $45^{\circ}$, the result implies that friction force due to fretting caused non-negligible cyclic stress at the fretting region.

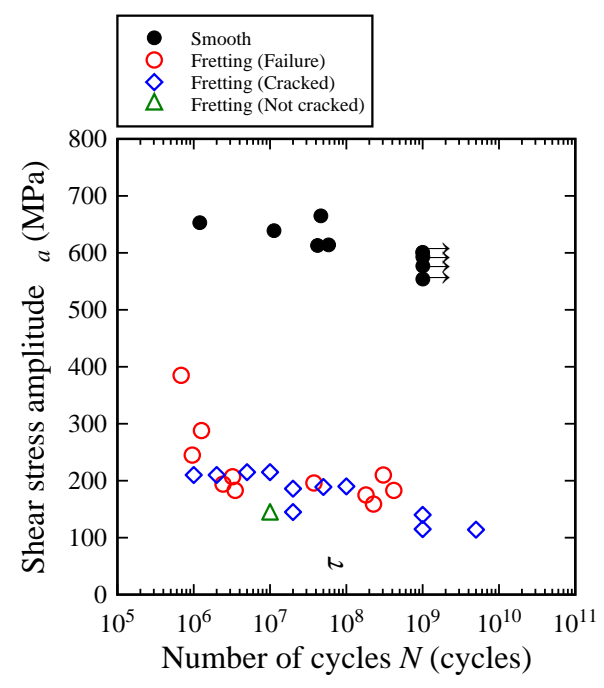

Fig. 4. S-N diagram.

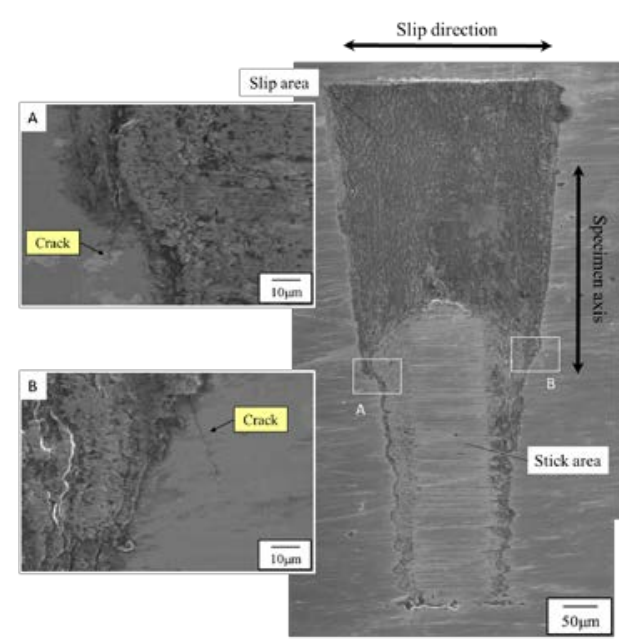

Fig. 5. Wear part of a specimen $\quad\left(\tau_{\mathrm{a}}=145 \mathrm{MPa}, N=1.0 \times 10^{9}\right.$ cycles $)$ 


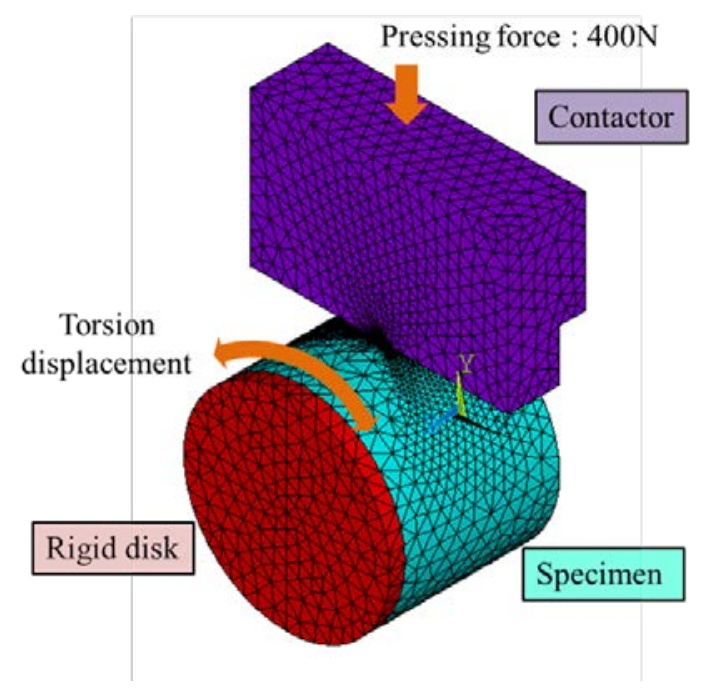

Fig. 6. FEM analytical model

\section{Conclusions}

In this study, an accelerated fretting fatigue testing method was developed by using an ultrasonic torsional fatigue testing machine with a clamping fretting pad. Fretting fatigue tests of quenched-tempered CrMo steel were conducted by using the developed method. Test results showed that fretting fatigue failure occurs in the very high cycle region.

\section{References}

1. Y. Shimamura, K. Narita, H. Ishii, K. Tohgo, T. Fujii, T. Yagasaki, M. Harada. Fatigue properties of carburized alloy steel in very high cycle regime under torsional loading. Int J Fatigue, 60: 57-62 (2014)

2. Z. D. Sun, C. Bathias, G. Baudry. Fretting fatigue of $42 \mathrm{CrMo} 4$ steel at ultrasonic frequency. Int J Fatigue, 23:449-53 (2001)

3. Y. Kondo, C. Sakae, M. Kubota, K. Yanagihara, Non-propagation crack at giga-cycle fretting fatigue limit. J Jpn Soc Mech Eng A, 70: 1066-70 (2004)

4. J. Q. Xu, S. Shirai, W. M. Tao, Y. Mutoh. Initiation and propafgation of fretting fatigue crack in the very long fatigue life. J Soc Mat Sci, Jpn, 51:808-13 (2002) 